\title{
Excreción de promastigotos de Leishmania pifanoi por Lutzomyia youngi experimentalmente infectada*
}

\author{
Excretion of promastigotos of Leishmania pifanoi by experimentally \\ infected Lutzomyia youngi
}

\author{
Elina Rojas, Jose V. Scorza y Alba Espinoza
}
Laboratorio de Quimioterápia y Control de Vectores, Centro de Investigaciones
Parasitológicas "José W. Torrealba" ULA-NURR. Venezuela

\begin{abstract}
Se describe el desarrollo poblacional promastigótico de Leishmania pifanoi en Lutzomyia youngi experimentalmente infectada y mantenida con sacarosa al $50 \%$ bajo condiciones constantes de temperatura y humedad. Se reconocen dos etapas para la diferenciación y el crecimiento de los parásitos entre las dos y ciento veinte horas postprandiales. Hasta 48 horas tiene lugar la diferenciación pleomórfica de amastigotos en promastigotos cortos, que se multiplican por división binaria hasta las 60 horas, cuando ocurre la ruptura de la membrana peritrófica. La segunda etapa tiene lugar entre las 72 y 96 horas cuando algunos parásitos migran hacia la válvula esofágica y los demás parásitos libres son excretados en gotitas fecales como promastigotos grandes y activos. Las primeras gotitas excretadas dan reacción positiva a glucosa o contienen cristales de urato. El exceso de promastigotos de la segunda fase de desarrollo es eliminado en las últimas excretas que dan reacción positiva con las pruebas Hemoscreen y Biuret para proteínas totales y también para glucosa, y constituyen el $82 \%$ del total de gotas excretadas. La excreción de parásitos por $L u$, youngi es fase normal del desarrollo de $L$. pitanoi en un vector.
\end{abstract}

Leishmania. Psichodidae, parasitologia. Relaciones hospedero-parásitos.

\section{Introducción}

Los primeros trabajos sobre el curso de la infección de Leishmania donovani en Phlebotomus argentipes (Short et al. ${ }^{9}, 1926$ ) y de $L$. infantum en $P$. perniciosus (Adler \& Theodor', 1931) describieron su desarrollo en la porción anterior del tubo digestivo, particularmente en el aparato bucal concluyendo que los ciclos de ambos parásitos eran continuamente progresivos, por lo menos hasta el noveno día de la infección, con activa multiplicación como promastigotos entre el tercero y quinto día, formando rosetas en el estómago, con final migración hacia el cardias y la faringe.

La excreción fecal de flagelados de $L$. mexicana mexicana, por Lutzomyia youngi (entonces considerada como $L$. townsendi), fue descrita por
Lugo \& Scorza ${ }^{\circ}$ (1982) a partir de las 60 y hasta las 132 horas postinfección.

Si el desarrollo de estos flagelados en los flebótomos vectores es contínuamente progresivo, cada etapa del proceso debe poseer su propio significado e incidir sobre el proceso subsiguiente (Shortt et al.", 1926). El estudio de tal secuencia, en parásitos morfológicamente similares y con escasa sincronización, es complejo e irregular atribuyéndose estas últimas condiciones a diferencias específicas entre los mismos parásitos o a diferencias entre las especies de flebótomos donde el proceso tiene lugar.

Este trabajo, contribuye a precisar detalles del desarrollo $L$, pifanoi en $L$. youngi desde las primeras 2 hasta las 120 horas, después de la ingesta infectante.

\footnotetext{
* Trabajo realizado con financiamiento del Provecto NURR-C.60-88.

Separatas/Reprints: Elina Rojas - Centro Trujilano de Investigaciones Parasitológicas "José W. Torrealba". Av. Camona Sector Los Ilustres, Aptdo. Postal 100. Trujillo 3102-Venezuela. Fax: 58-72-33503.

Recebido em 20.3.1995. Aprobado en 31.5.1995
} 


\section{Material y Metodo}

1. Parásitos. Leishmania pifanoi ( $\mathrm{H}$ HOM/NE/86/MH) aislados por la Dra Olinda Delgado de un caso de leishmaniasis difusa, con desarrollo suprapilórico en $L$. youngi y confirmado por PCR por la Dra. Palmira Guevara.

2. Flebótomos. Hembras silvestres de Lutzomyia youngi (Murillo y Zeledon, 1985) capturadas en períodos de eclosión poblacional (Abril-Mayo y Julio-Agosto) con trampa de Shannon en una localidad a 1300 m.s.n.m., no endémica para leishmaniasis. También se utilizó Lu. youngi nacidas en el laboratorio.

3. Infección de los flebótomos. Alimentándolos sobre lesiones tarsales de 30 días de evolución en hámsteres machos. Se conservaron los insectos en envases de vidrio acorchados interiormente (Lugo \& Scorza ${ }^{6}, 1982$ ) dentro de cajas de poliestireno con humedad de $80 \%$ y $24^{\circ} \mathrm{C}$.

4. Desarrollo de $L$. pifanoi en $L$. youngi entre 2 y 48 horas postprandiales.

Se disecaron insectos ingurgitados dilacerando el contenido de cada estómago, con ruptura de la membrana peritrófica sobre una gota de solución de albúmina bovina al $10 \%$ en solución salina al $0,6 \%$. Secada la preparación, se tiñó con Giemsa al $5 \%$ en tapón de fosfato $\mathrm{M} / 200$ a $\mathrm{pH} 7.2$ durante una hora y se la lavó cuidadosamente con agua destilada evitando el desprendimiento del material. Se examinó la preparación, bajo aumento $100 \mathrm{X}$ con inmersión. Se disecaron insectos a las $2,4,8$, 17,22 y 48 horas de digestión postprandial y se midieron, cada vez, más de 20 parásitos.

5 . Estudio de las excretas de $L$. youngi infectadas con L. pifanoi.

Tres lotes de 40,60 , y 70 hembras silvestres de Lu. youngi fueron alimentadas sobre lesiones tarsales de hámsteres. Las excretas de los insectos que reposaron sobre el revestimiento interno de corcho, fueron recogidas a las 24 y luego cada 12 horas postprandiales hasta 120 horas, sobre láminas de vidrio de $50 \times 50 \mathrm{~mm}$ que se cambiaron cada vez. Los insectos fueron sobrealimentados con sacarosa comercial al 50\%. Las gotitas de excretas se fijaron con metanol absoluto para teñirlas con Giemsa al $10 \%$ en tampón de fosfato $\mathrm{M} / 200$ a $\mathrm{pH} 7,2$.

6. Estudio de la excreción de $L$. youngi infectados con L. pifanoi y aisladas individualmente.

Se utilizó $L$, youngi nacidas en el laboratorio y silvestres, alimentadas sobre hámsteres infectados con L. pifanoi. Una vez ingurgitados fueron mantenidos individualmente dentro de cílindros de vidro, recubiertos internamente con corcho de $2 \mathrm{~mm}$ de espesor y $15 \mathrm{~mm}$ de diámetro, con un porta-objeto a modo de fondo inferior y tela fina de nylon cubriendo en el extremo superior. Los porta-objetos fueron sustituidos cada 12 horas para contar las deyecciones. El estudio sobre la naturaleza de las excretas se hizo con microtests de Biuret $y$ Hemoscreen para proteínas y para glucosa. Se estudió separadamente 20 hembras de colonia y 20 hembras silvestres que fueron investigadas desde las 24 hasta las 120 horas, cuando se retiró la novena lámina y se disecó cada hembra sobreviviente para precisar si estaba infectada o no. La presencia de flagelados en los insectos fue constatada por examen en fresco con 450X. El estudio morfométrico de los parásitos se hizo en las mismas láminas fijadas con metanol, teñidas con Giemsa al $10 \%$.

\section{Resultados}

\section{Diferenciación y Pleomorfismo, Hasta 48 Horas de Desarrollo de $L$ u pifanoi en $L u$, youngi}

En la Figura 1 se presentan esquemáticamente los estadios de diferenciación de amastigotos en promastigotos de L. pifanoi en los frotes de contenido estomacal junto con los valores porcentuales de dichas formas, y el número de parásitos examinados.

\begin{tabular}{|c|c|c|c|c|c|c|}
\hline $\begin{array}{l}\text { Horas } \\
\text { después } \\
\text { de la } \\
\text { ingurgi- } \\
\text { tación }\end{array}$ & $\theta$ & 9 & $\phi$ & 9 & $\theta_{\infty}^{\infty}$ & $\begin{array}{c}\text { Numero } \\
\text { de } \\
\text { formas }\end{array}$ \\
\hline 2 & 55 & 10 & - & 22 & 13 & 15 \\
\hline 4 & 11 & 44 & . & 18 & 22 & 180 \\
\hline 8 & . & - & 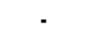 & 29 & 71 & a? \\
\hline 17 & - & - & 37 & 18 & 47 & 176 \\
\hline 22 & - & 1 & 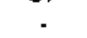 & 20 & 78 & 312 \\
\hline 48 & & - & & & 100 & 108 \\
\hline
\end{tabular}

Figura 1 - Pleomorfismo y diferenciación de $L$. mexicana en $L$. youngi entre las dos y cuarenta $y$ ocho horas de postinfección.

Se detectó un pleomorfismo con predominio de amastigotos y su transformación en promastigotos cortos, indivisos entre las 2 y 4 horas. Formas de división de amastigotos o de promastigotos flagelados, se vieron en bajo porcentaje $(73 \%)$ entre las 2 y 4 horas siendo más frecuentes a partir de las 8 horas. Entre las 17 y 48 horas se incrementó la frecuencia y el número de promastigotos en división, llegando a formar rosetas ( $25 \%$ ). 
Tabla 1 - Excretas blancas, negras y transparentes eliminadas por L. youngi entre 24 y 120 horas, con indicación de las contaminadas con promastigotos de L. mexicana.

Numero del experimento y Periodos de

Excretas por lámina

Excretas con flagelados por lámina

de las hembras de

excreción

entre horas Blancas Negras Transp. Totales Blancas Negras Transp. Totales

L. youngi por envase

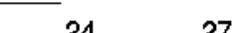

N: 40

24
48
-60

Excretas/Flebótomo: $24,5 \quad 61,5 \quad 72$

Excretas positivas por

Flebótomo

$\begin{array}{rr}6,9 & 96 \\ 108\end{array}$

27
30
66

$\begin{array}{rrr}6 & - & 33 \\ 18 & 1 & 49 \\ 234 & 60 & 360\end{array}$

$46 \quad 137 \quad 60 \quad 243$

$\begin{array}{rrrr}46 & 137 & 60 & 243 \\ 49 & 20 & 88 & 157\end{array}$

$\begin{array}{llll}8 & 1 & 81 & 90\end{array}$

$\begin{array}{llll}1 & - & 18 & 19 \Sigma \\ - & - & 30 & 3098\end{array}$

\begin{tabular}{|c|c|c|c|}
\hline - & - & - & - \\
\hline - & - & - & - \\
\hline$=$ & 30 & 60 & 90 \\
\hline - & 1 & 20 & 21 \\
\hline . & 7 & 86 & 9342,3 \\
\hline - & . & 67 & 67 \\
\hline - & - & - & $-\quad+$ \\
\hline- & - & 1 & 1274 \\
\hline
\end{tabular}

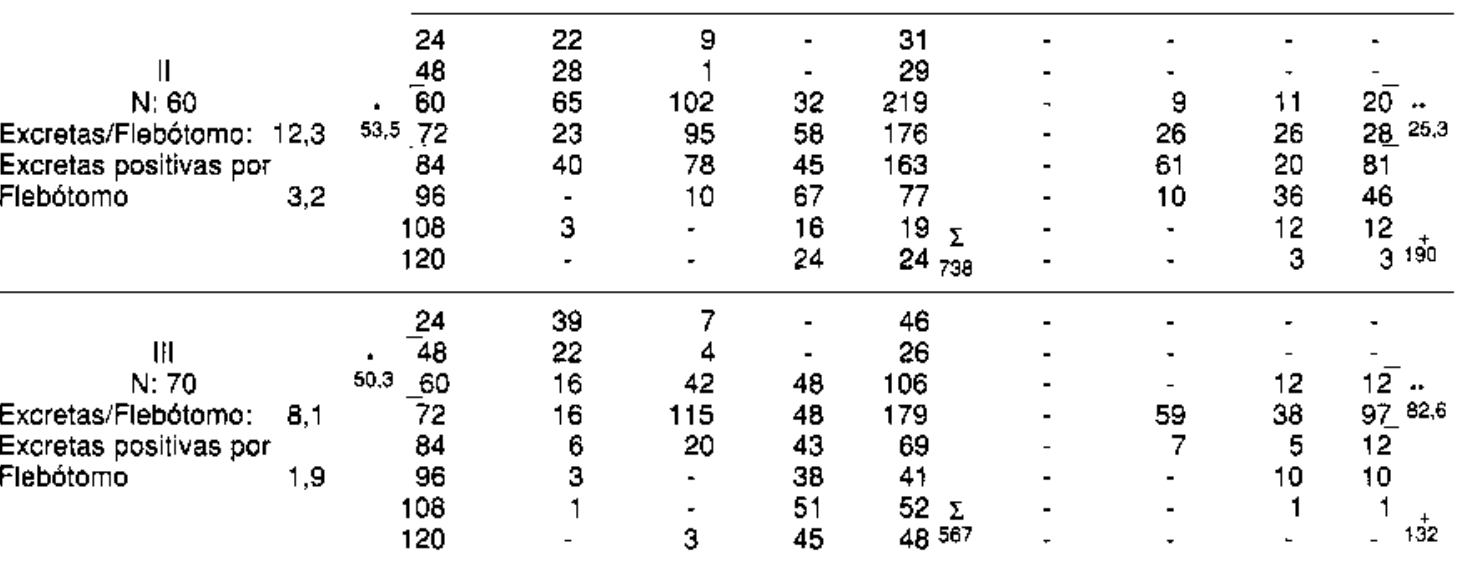

* Porcentaje del total de excretas entre 60 y 72 horas $\quad \Sigma=$ total

* Porcentaje del total de excretas con parasitos entre 60 y 72 horas

Excreción de Promastigotos de $L$ pifanoi por $L$. youngi Mantenidas en Grupo
Se utilizaron 3 lotes de 40,60 y 70 hembras silvestres de $L$ youngi para contar gotitas excretadas

Tabla 2 - Excretas eliminadas por $L$. youngi aislados entre 24 y 120 horas postingestión señalándose las gotitas con L. mexicana (en circulos).

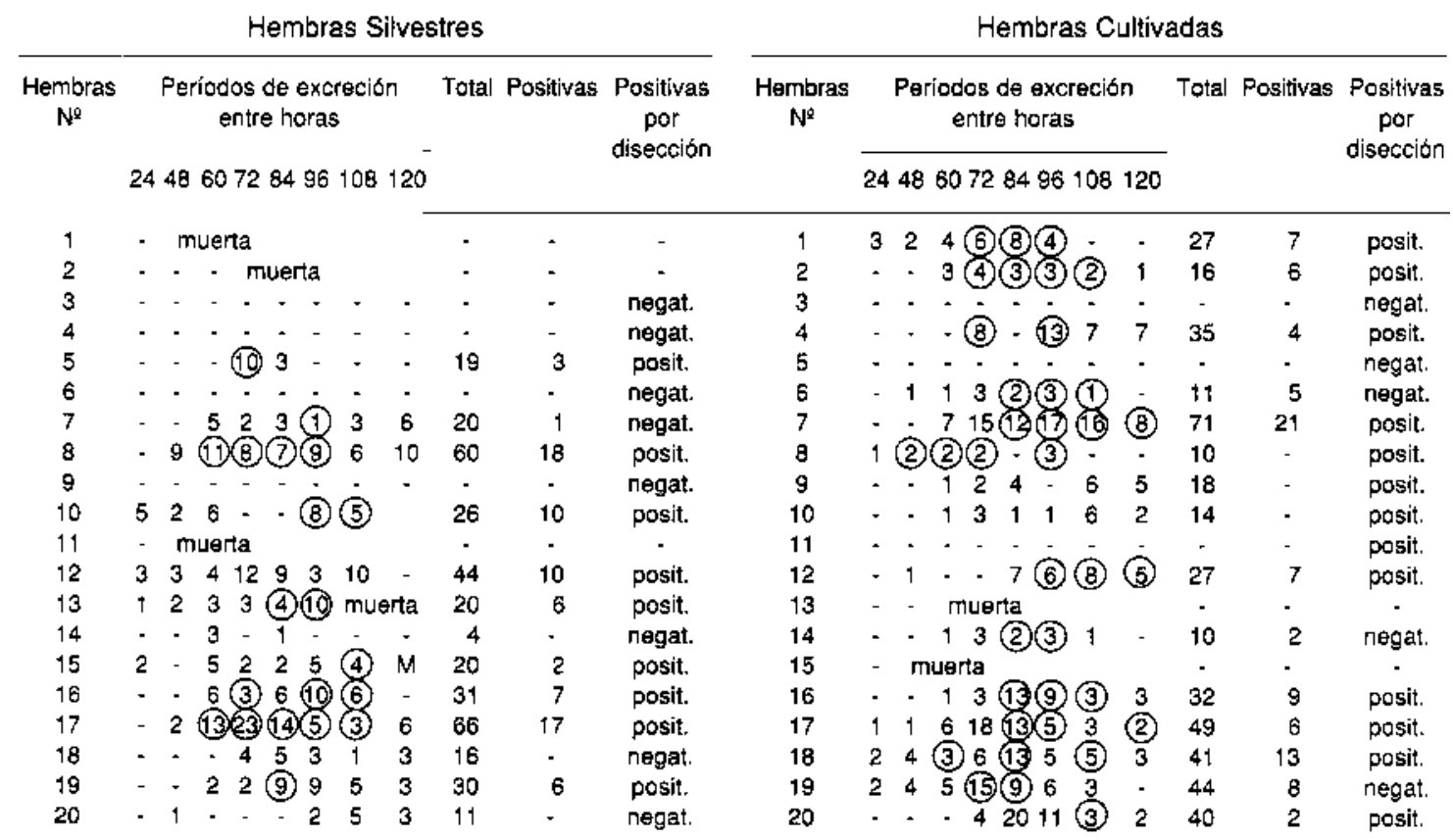




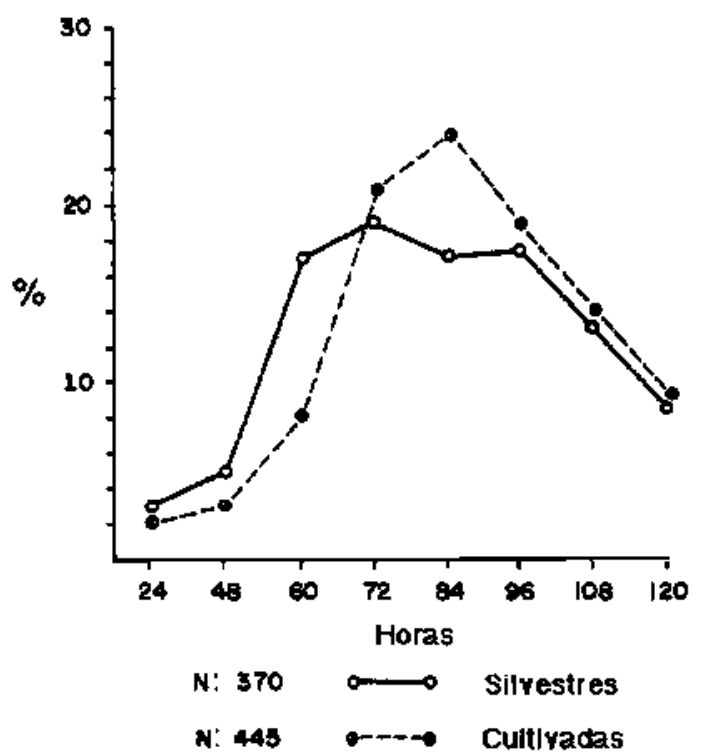

Flgura 2 - Frecuencias porcentuales de excreción de gotitas por $L$, youngi.

entre las 24 y 120 horas después de la ingesta infectante. Se distinguen excretas blancas u orina, negras o heces con hemina y transparentes con azúcar. Los resultados se presentan en la Tabla 1 con señalamiento de las gotitas contaminadas con promastigotos.

El más alto porcentaje de excretas de cualquier naturaleza ocurrió, en los tres lotes, entre las 60 y 72 horas y fue siempre mayor del $50 \%$ en este lapso. El número de gotitas totales excretadas por flebotomo, fue de $24,5,12,3$, y 8,1 respectivamente. La data sobre excretas contaminadas con promastigotos se presentan en las Tablas 1 y 2 en columnas a la derecha. El más alto porcentaje de excretas positivas ocurrió entre las 60 y 72 horas, siendo respectivamente de $42,3,25,3$ y 82,6 . El número de gotitas excretadas por flebótomos y el de las contaminadas con promastigotos, es inversamente proporcional al número de $L$. youngi confinados por envase, de $6,9,3,2$ y 1,9 respectivamente el número de gotitas con parásitos.

\section{Excreción de Flagelados por Hembras Aisladas}

Para estudiar posibles efectos de hacinamiento y descartar los debidos a la edad cronológica en las hembras silvestres se hizo un tercer experimento con 20 hembras capturadas la noche anterior a la infección y 20 hembras de cultivo con edades entre 2 y 6 días.

Las mortalidades espontáneas, y los porcentajes de infección son similares entre hembras silvestres o de cultivo (Tabla 2).
En las hembras silvestres, de 15 sobrevivientes a las 120 horas, 10 fueron positivas por excreción y 9 sólamente mostraron flagelados por disección. De 20 hembras de cultivo 18 sobrevivieron hasta 120 horas, 13 fueron positivas por disección, y 12 habían eliminado flagelados. Otras 3 con heces positivas resultaron negativas a disección, lo cual sugiere que eliminaron todos los flagelados por excreción.

Las hembras silvestres hicieron 24,7 excretas por flebótomo, en tanto que las de cultivo eliminaron 21,8 gotitas por hembra.

Las silvestres eliminaron 6,2 gotas positivas por hembra y las de colonia 6,0 gotitas por individuo.

Los períodos de mayor actividad excretora, se ilustran en ta Figura 2. En las silvestres, el $70 \%$ de las deyecciones se expulsaron entre las 60 y 108 horas, mientras que en las de colonia ocurrió en un $64 \%$ entre las 72 y 96 horas.

Al final de los experimentos con excepción de parásitos formando tapones faríngeos, no se hallaron otros flagelados en el tubo digestivo, aunque excepcionalmente se vieron muy escasas formas inmóviles en ampolla rectal.

\section{Morfometria de Promastigotos de $L$ pifanoi Excretados por Lu. youngi}

Se contó el número de flagelados eliminados en las gotitas de excretas de $L u$. youngi silvestres o de colonia, y su cantidad varió desde decenas hasta

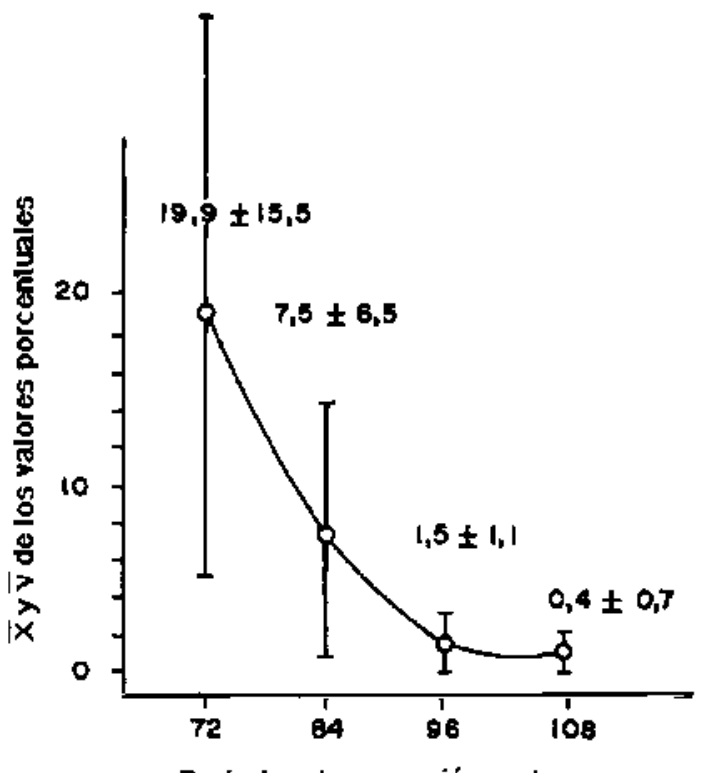

Períodos de excreción en horas

Figura 3 - Porcentuales de formas en división en promastigotos de $L$. mexicana excretados por $L$. youngi ontre 72 y 108 horas postingesta infectante. 

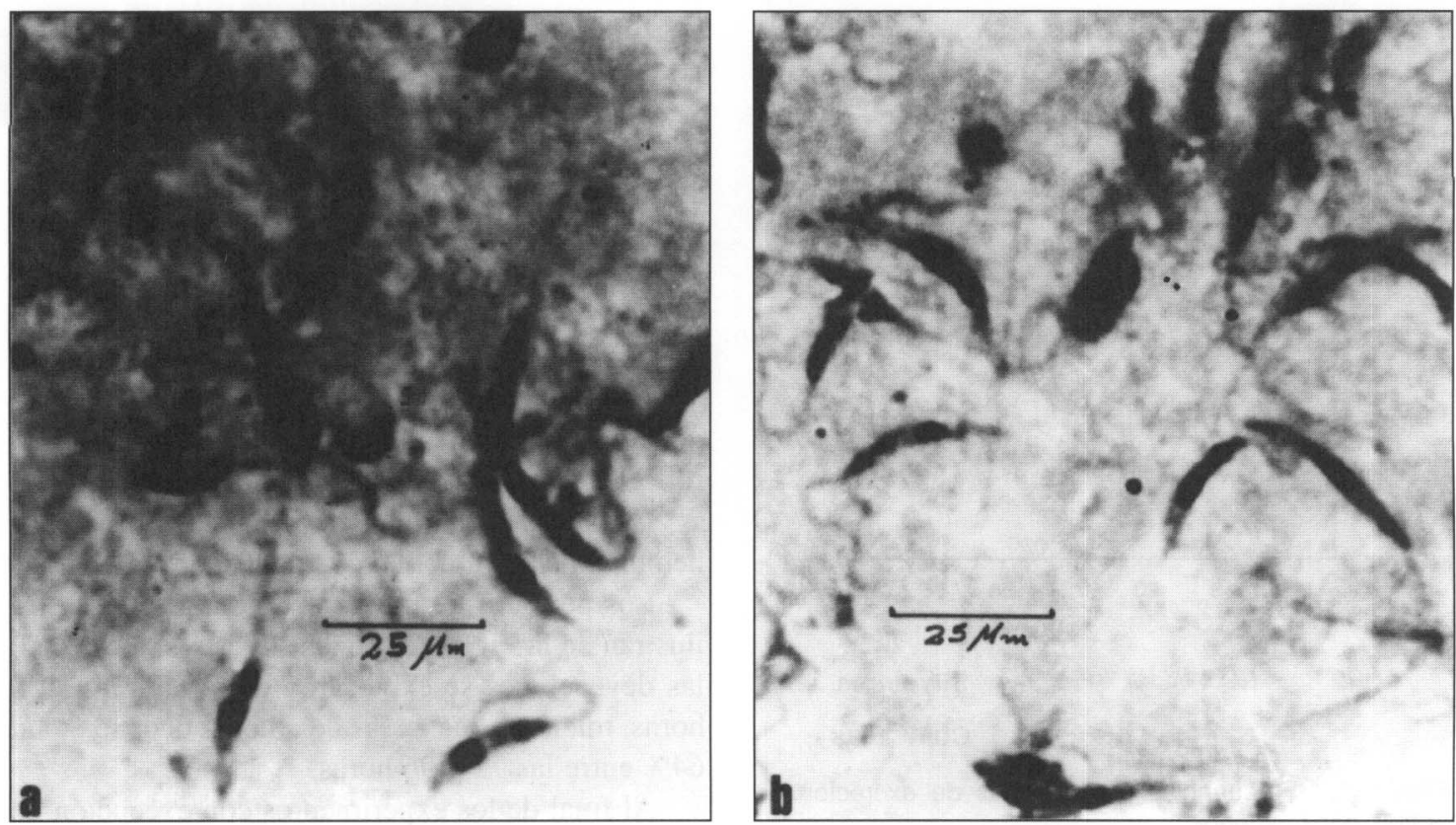

Flgura 4 - Forma y tamaño de parásitos en excretas de Lutzomyia youngi a las 72 horas post-infección con Leishmania mexicana.

centenares. Los flagelados se hallaron sólamente en las deyecciones negras o en las transparentes y nunca en las excreciones con uratos. En las deyecciones transparentes, los promastigotos fueron mejor observados

Se contaron los parásitos en división, en gotitas eliminadas entre las 72 y $108 \mathrm{~h}$ y se examinaron cada vez más de 500 parásitos claramente visibles en el borde de las gotas, para diferenciar los que se hallaron en división con dos núcleos, dos cinetoplastos o con dos flagelos. En la Figura 3 se ilustraron medias y varianzas calculadas para las formas en división entre 72 y $108 \mathrm{~h}$ cuando disminuye cuasi exponencialmente el número de parásitos en división y no se detectan parásitos en división a partir de las 96 horas. Son promastigotos monomórficos, grandes, anchos, con núcleo esférico u ovalado y cinetoplasto voluminoso (Fig.4a y b). La medida de 28 hasta 35 parásitos dió $23,6 \pm 7,6 \mu \mathrm{m}$ de longitud total para el soma y $22,0 \pm 5,3 \mu \mathrm{m}$ para el flagelo.

\section{Discusión}

Adler \& Theodor' (1931) describieron flagelados largos de $L$ infantum en $P$. perniciosus, con 22 hasta $30.5 \mu$ de longitud y con flagelos relativamente más cortos que la longitud del soma, numerosos en el digestivo medio entre los 2 y 6 días después de la ingesta infectante. Shortt ${ }^{9}$ et al. (1926) señalaron que a las 72 horas, en $P$. argentipes infectados con $L$, donovani, los flagelados eran alargados y activamente móviles, con multiplicación evidente por la formación de rosetas en grandes proporciones. Después del 3er día, que pareció marcar una fase definitiva, hallaron diferentes estadíos aunque en pequeño número. Los autores coinciden en señalar la súbita disminución de la población de parásitos largos y móviles.

Usando microscopía de rastreado, Warburg ${ }^{14} e t$ al. (1986), en infecciones de tres de días en $P$. $p a$ patasi por L. major, ilustran enjambres desde 200.000 hasta 800.000 promastigotos libres de 15 a $20 \mu \mathrm{m}$ de largo en el estómago medio y al mismo tiempo alfombras de parásitos más cortos, con 5 a $7 \mu \mathrm{m}$ de longitud, adheridos a la válvula estomodeal y al esófago, donde el polimorfismo contrasta con el monomorfismo de los estadios largos y libres. Aunque se discute la importancia del polimorfismo, su relación con los opistomastigotos y paramastigotos y también con formas pequeñas con largos flagelos cuya importancia consideran crucial para la transmisión por picadura, no hay información con respecto a los largos promastigotos de cortos flagelos existentes en el estómago medio, cuando ya la válvula estomodeal está saturada por otras formas.

Lawyer $^{5}$ et al. (1987) estiman, en medio millón el número de promastigotos largos y altamente móviles de L. mexicana en Lu. diabólica a las 72 horas de desarrollo. Describen, masas de flagela- 
dos envueltos por una matriz gelatinosa adheridos a la válvula estomodeal y plantean que la asociación de nectomonas grandes con las microvellosidades del estómago, impedirían su excreción con la ingesta digerida; es la única referencia con respecto a estas formas y más aparece sugerir su retención, que su expulsión. Walters ${ }^{13}$ et al. (1989), referiéndose a $L$. brazilensis panamensis parásito que se adhiere a las crestas pilóricas de Lutzomyia gomezi, distinguen dos tipos de promastigotos nectomonados, unos cortos y espatulados con $5-8 \mu \mathrm{m}$ de longitud somática y otros más largos, con 13 hasta $19 \mu \mathrm{m}$, que "aparentemente representan productos finales de la multiplicación" y señalan que ninguna de estas formas se interdigita con las microvellosidades, ni parece ocupar el nicho del digestivo medio por más tiempo, después de la ruptura de la membrana peritrófica.

La enorme masa de nectomonas largas y activamente móviles cuyo destino es controvertido, pudiera ser retenida por las microvellosidades del tubo digestivo medio aunque no se interdigiten con ellas y desplazarse hacia el píloro, como producto final del ciclo vital de los parásitos, sin ocupar espacio físico o nidal alguno. Lainson \& Shaw (1988), al estudiar el desarrollo de $L$. chagasi en Lutzomvia longipalpis, señalaron la presencia de numerosos promastigotos alargados e indivisos, identificados como las formas $\mathrm{a}^{2} \mathrm{P}$, sin explicar su destino o función.

Se confirmaron observaciones ya publicadas por Lugo \& Scorza ${ }^{6}$ (1982) sobre el fenómeno de la excreción de flagelados no se funcionales por Lutzomyia youngi infectados con diferentes especies de Leishmania suprapiloricas y peripilóricas.

Siendo este fenómeno parte importante de su desarrollo en flebótomos, considera que con la excreción de las nectomonas monomórficas, culmina la fase exponencial de crecimiento, coincidiendo ello con el inicio de una fase estacionaria que a su vez concluiría con la producción de parásitos infectantes por picadura natural.

Los flagelados tripanosomátinos comprenden un complejo conjunto de géneros de parásitos monoxénicos o heteroxénicos bien caracterizados por su morfología (Wallace ${ }^{\prime 2}, 1966$ ). Las formas parásitas de invertebrados concluyen sus ciclos en estación posterior y se propagan por contaminación fecal dentro de la población de hospedadores (Wallace'², 1966).

Entre los Trypanosomatidae heteroxénicos más primitivos, Sauroleishmania spp., por su parasitismo en reptiles y su evolución en Sergentomyia spp. (Killick-Kendrick et $\mathrm{al}^{2}$., 1986) con presencia de amastigotos en la sangre de reptiles (Telford ${ }^{10}, 1979$ ) constituye un ejemplo de parásitos con estación posterior siendo típica $S$. tarentolae del gecko Tarentola mauritanica, con desarrollo en Phlebotomus sp. (Vickerman ${ }^{11}, 1965$; Pozio ${ }^{8}$ et al., 1986).

$L a$ excreción de nectomonadas grandes por $L$. pifanoi al final de la digestión de la ingesta sanguínea infectante de Lu. youngi, además de ser un fenómeno general y común en otras especies, está determinada por la cinética y la aparición de un excesivo número de promastigotos en el estómago medio (Molineux et al',, 1986). En algunos casos, como acontece en las especies de Viannia la colonización del píloro es parte importante del ciclo natural (Lainson et $\mathrm{al}^{4}$., 1977) y se presume que tales haptomonadas pilóricas puedan migrar eventualmente hasta la porción anterior del tubo digestivo.

Es especulable que las nectomonadas excretadas en gotitas azucaradas constituyan una fuente de contaminación entre flebótomos por la gran avidez de estos insectos por azúcares y su tendencia a reposar en grupos en los refugios naturales. Se ha tenido la oportunidad de examinar gotitas fecales azucaradas contaminadas y recientemente expulsadas, y constatar presencia de parásitos con activos movimientos.

En conclusión la ingestión de amastigotos de Leishmania pifanoi por $L$ youngi, junto con sangre del hospedador, conduce a la diferenciación hasta promastigotos, cuya fase de crecimiento exponencial, dentro del estómago con o sin membrana peritrófica intacta y a juzgar por el número de formas en división, concluye hacia las $96 \mathrm{~h}$. Entre las $24 \mathrm{~h}$ y hasta las 96 h después de la ingesta, los flebótomos excretan gotitas fecales blancas con uratos, gotas oscuras con restos de hemina y gotas transparentes conteniendo glucosa. Entre las 60 y $96 \mathrm{~h}$, en las gotitas de los dos últimos tipos se eliminan promastigotos grandes y monomórficos. La eliminación fecal de promastigotos en exceso, al final de la digestión de sangre, es fase obligada del desarrollo del parásito.

\section{Agradecimientos}

A la Dra. Olinda Delgado, del Instituto de Medicina Tropical "Félix Pifano" Caracas, la cepa de Leishmania pifanoi MH-86- que sirvió como base para este estudio; a la Dra. Palmira Guevara de la L.C.V. por su interés para la identificación del parásito y del Dr. Rafael Bonfante de U.C.L.A. por la donación de los animales experimentales, sin los cuales no hubiera sido posible mantener la cepa en las condiciones para nuestro ensayo. 


\section{Referencias Blbliográficas}

1. ADLER, S. \& THEODOR, O. Investigations on the Mediterranean Kala-Azar. IV- Infection of Sandflies with Leisbmania infantum. Natural parasites of wild sandflies in Catania. Observations on Trypanosoma platydactyli Catonillar. Proc. $R$. Soc., 8: 48193, 1931.

2. KILLICK-KENDRICK; R.; LAINSON, R.; RIOLX, J.A.; SAFJANOVA, V. M. The taxonomy of Leisbmania - like parasites of reptiles. In: Colloque International, Leishmania. Taxonomie et pbylogenèse; Applications écoépidêmiologiques. 1984. Montpellier, IMEEE, 1986. p. 143-8.

3. LAINSON, R. \& SHAW, J. J. Observations on the development of Leishmania (L) chagasi Cunha and Chagas in the midgut of the sandfly vector Lutzomyia longipalpus (Lutz and Neiva). Ann. Parassitol. Hum. Comp., 63: 134-45, 1988.

4. LAINSON, R; WARD, R. D.; SHAW, J. J. Experimental transmission of Leisbmania chagasi causative agent of neotropical visceral leishmaniasis, by the sandfly Lutzomyta longipalpis. Nature, 266: 628-30, 1977.

5. LAWYER, P.; YOUNG, D.; BUTLER, J.; AKIN, D. Development of Leisbmania mexicana in Lutzomyia sbannoni (Diptera:Psychodidae). J. Med. Entomol, 24: 347-55, 1987.

6. LUGO de Y. A. \& SCORZA, J. V. Ensayos metodológicos para la investigación de reservorios de Leisbmania spp. en Los Andes venezolanos. Mem. Inst. Oswaldo, Cruz, 77; $367-84,1982$.
7. MOLYNEUX, D. H.; RYAN, L.; LAINSON, R.; SHAW, J. J. The Leisbmania-sandfly interface. In: Colloque International, Leisbmania. Taxonomie et pbylogenèse; Applications écoépidémiologiques. 1984. Montpellier, IMEEE, 1986. p. 311-24.

8. POZIO, E.; GRAMICIA, $\mathrm{L}_{\text {; }}$ Maroli, M. Hemoflagellés de Tarentola mauritanica L., 1758 (Reptilia, Gekkonidae). In: Colloque International. Leishmania. Taxonomie et phylogenèse; A pplications éco-épidémiologiques. 1984. Montpellier, IMEEE, 1986, p. 149-5.

9. SHORT, H. E. \& BARRAND, P. J. The life history and morphology of Heppetomonas donovani in the sandfly Pblebotomus argentipes. Ind.J. Med. Res., 13: 947-59, 1926.

10. TELFORD, S.R. Evolutionary implications of Leishmania amastigotes in circulatory blood cells of lizards. Parasitola, 79: 317-24, 1979.

11. VICKERMAN, $\mathrm{K}$. The identify of Leisbmania cbamaelconis Wenyon, 1921: laboratory demonstration. Trans. R. Soc. Trop. Med. Hyg., 59: 372, 1965.

12. WALLACE, F. G. The trypanosomatides parasites of insects and arachnids. Exptl. Parasitol, 18: 124-93, 1966.

13. WALTERS, L. L.; CHAPLIN, G. L.; MODI, G. B.; TESH, R. Ultrastructural biology of Leishmania (Viannia) panamensis in Lutzomyia gomezi (Diptera:Psychodidae) a natural host-parasite association. Am.J. Trop. Med. Hyg., 40: 19-39, 1989.

13. WARBURG, G. S. H.; SCHELI, Y.; SAIRE, D. Scanning electron microscopy of Leishmania major in Pblebotomus papatasi.Parasitenk., 72: 423-31, 1986 .

\begin{abstract}
The increase in the promastigotes population of Leishmania pifanoi in Lutzomyla youngi experimentally infected and kept on 50\% sacarose under constant conditions of temperature and humidity is described. Two stages in the differentation and growth of the perasites are recognised between two and twenty-four hours after meals. The pleomorphic differentiation of the amastigotes in short promestigotes which multiply by binary division for 60 hours, when the rupture of the penitrophic membrane occurs, takes place within 48 hours. The second stage occurs between 72 and 96 hours when some of the parasites migrate to the esophagic valve and the rest of the free parasites are excreted in fecal drops as large, active promastigotes. The first drops excreted react positively to glucose or contain crystals of urate. The excess promastigotes of the second stage of development are eliminated in the last excretions and react positively to the Hemoscreen and Biuret tests for total proteins as also for glucose and account for $82 \%$ of the of drops excreted. The excretion of parasites by Lu. youngi is a normal stage in the growth of L. pifanoi into a vector.
\end{abstract}

Leishmania. Psychodidae, parasitology. Host-parasite relations. 